University of Nebraska - Lincoln

DigitalCommons@University of Nebraska - Lincoln

EFFECT OF HYDRODYNAMIC PRESSURE TREATMENT AND COOKING ON INACTIVATION OF ESCHERICHIA COLI 0157:H7 IN BLADE-TENDERIZED BEEF STEAKS

\author{
J. R. Patel \\ USDA
}

A. C. Williams-Campbell

USDA

M. N. Liu

USDA

M. B. Solomon

USDA

Follow this and additional works at: https://digitalcommons.unl.edu/usdaarsfacpub

Patel, J. R.; Williams-Campbell, A. C.; Liu, M. N.; and Solomon, M. B., "EFFECT OF HYDRODYNAMIC PRESSURE TREATMENT AND COOKING ON INACTIVATION OF ESCHERICHIA COLI 0157:H7 IN BLADETENDERIZED BEEF STEAKS" (2005). Publications from USDA-ARS / UNL Faculty. 1439.

https://digitalcommons.unl.edu/usdaarsfacpub/1439

This Article is brought to you for free and open access by the U.S. Department of Agriculture: Agricultural Research Service, Lincoln, Nebraska at DigitalCommons@University of Nebraska - Lincoln. It has been accepted for inclusion in Publications from USDA-ARS / UNL Faculty by an authorized administrator of DigitalCommons@University of Nebraska - Lincoln. 


\title{
EFFECT OF HYDRODYNAMIC PRESSURE TREATMENT AND COOKING ON INACTIVATION OF ESCHERICHIA COLI O157:H7 IN BLADE-TENDERIZED BEEF STEAKS*
}

\author{
J.R. PATEL, A.C. WILLIAMS-CAMPBELL, M.N. LIU and M.B. SOLOMON ${ }^{1}$ \\ Food Technology and Safety Laboratory \\ Beltsville Agricultural Research Center \\ Agriculture Research Service, USDA \\ Beltsville, MD 20705-2350
}

Accepted for Publication November 10, 2004

\begin{abstract}
The efficacy of hydrodynamic pressure (HDP) treatment for inactivation of Escherichia coli O157:H7 in blade-tenderized beef steaks was studied. Beef steaks $(\mathrm{N}=48)$ were inoculated with a five-strain cocktail of Escherichia coli O157:H7 and treated with blade tenderization (BT), HDP or a combination of $B T$ followed by HDP (BTH). Control and treated steaks were cooked to $54.4 C$ (undercooked), 62.8C (medium rare) and 71.1C (medium) on open-hearth Farberware grills. HDP treatment reduced E. coli O157:H7 populations by $0.3 \log _{10} \mathrm{cfu} / \mathrm{g}$, which was not different $(\mathrm{P}>0.05)$ from untreated controls. At each endpoint cooking temperature, E. coli O157:H7 survival was always higher in BT-treated steaks than in untreated steaks cooked to corresponding temperatures. This could be due to migration of surface bacteria to the interior of the muscle thereby protecting bacteria from the lethality of heat. E. coli O157:H7 populations in BTH-treated steaks cooked to 71.1C were nondetectable and were significantly different from BT-treated steaks cooked to 71.1C. Results suggest that BT of intact beef muscle does transfer surface bacteria to the interior of the muscle, which would necessitate a combination of elevated cooking temperatures $(>71.1 C)$ and a treatment like HDP for inactivation of bacteria.
\end{abstract}

* Mention of trade names or commercial products does not imply recommendation or endorsement to the exclusion of other products by the U.S. Department of Agriculture.

${ }^{1}$ Corresponding author. TEL: (301) 504-8400; FAX: (301) 504-8438; EMAIL: jpatel@ anri.barc.usda.gov 


\section{INTRODUCTION}

Meat and food companies must consider the evolution of purchasing and consumption habits of consumers, as well as the perception and trends of consumer demands to keep or reinforce their leading position in the industry. Consumers demand high quality (tender), safe, minimally processed fresh meats. Blade tenderization (BT) is commercially utilized to increase tenderness by partial severance of both connective tissue and muscle fibers, which leads to lower shear force and easier mastication (Miller 1975). Phebus et al. (1999) studied microbial hazards due to BT treatment of intact muscle, which might introduce pathogens into the interior of the muscle. They reported that although 3-4\% of the inoculated Escherichia coli $\mathrm{O} 157: \mathrm{H} 7$ were transferred to the interior of steaks after BT treatment, cooking to an internal temperature of $60 \mathrm{C}$ or higher in a kitchen oven at 260C (ambient oven temperature of about 149C) destroyed nearly all of the pathogenic populations.

Many nonthermal preservation technologies with potential in the meat industry, like high pressure processing (HPP), oscillating magnetic fields, high intensity pulsed light, X-rays and electron beams have been investigated (Hugas et al. 2002). These technologies have the goal of being lethal to pathogenic and spoilage bacteria while maintaining the quality of the meat. Hydrodynamic pressure (HDP) processing is an innovative nonthermal technology developed for improving meat tenderness (Solomon et al. 1997). The process uses a high-energy explosive to generate supersonic shockwaves in a liquid medium. The shockwaves pass through the liquid media and boneless meat, which is an acoustical match with water (Kolsky 1980) due to its high moisture content, while reflecting off any objects that are not an acoustical match. The shock waves generated in the HDP process cause significant disruption of myofibrillar proteins in muscle tissue, resulting in improved tenderness of various beef cuts (Solomon 1998; Zuckerman and Solomon 1998). The same shock waves generated during the HDP process causing tenderization of muscle foods may also exert a bactericidal effect. HDP treatment has been shown to reduce spoilage bacteria on the surface of beef stew pieces (Williams-Campbell and Solomon 2002), on pork stew pieces and in ground beef (Williams-Campbell and Solomon 2000), and inactivation of $T$. spiralis in pork loins (Gamble et al. 1998). While HDP treatment has been utilized to explore its bactericidal effects on natural, nonpathogenic microorganisms in meat, its effect on pathogenic E. coli $\mathrm{O} 157: \mathrm{H} 7$ has not been determined.

Escherichia coli $\mathrm{O} 157: \mathrm{H} 7$ is one of the most important foodborne pathogens and has been responsible for several outbreaks associated with consumption of ground beef (Griffin and Tauxer 1991; Meng and Doyle 1998) and intact or blade-tenderized roast beef (Sporing 1999). Two outbreaks associated 
with Salmonella in meat have been traced to a combination of BT and undercooking (Anonymous 1969). Recently, more than $300,000 \mathrm{~kg}$ of bladetenderized and injected whole-muscle cuts meat were recalled due to $E$. coli O157:H7 related illness (Anonymous 2003). Recalls and outbreaks associated with consumption of $E$. coli $\mathrm{O} 157: \mathrm{H} 7$ contaminated, blade-tenderized beef is a concern for the food industry. An intervention step to reduce E. coli $\mathrm{O} 157: \mathrm{H} 7$ populations transferred into interior beef muscle during BT would help avoid public health hazards, recalls and outbreaks. The objective of this study was to investigate the effectiveness of HDP treatment in combination with cooking in reducing E. coli $\mathrm{O} 157: \mathrm{H} 7$ populations following BT of artificially contaminated beef strip loins.

\section{MATERIALS AND METHODS}

\section{Bacterial Strains}

A five-strain cocktail of Escherichia coli O157:H7 was used for this study. Strain 43888 was obtained from the American Type Culture Collection (ATCC, Manassas, VA). Strain C9490, the Jack-in-the-Box outbreak isolate associated with beef hamburger, was obtained from USDA Eastern Regional Research Center, Wyndmoor, PA. Three strains, 3027-96 (isolated from patients with diarrhea in Nebraska), 3055-93 (isolated from patients with hemolytic uremic syndrome in Louisiana) and C7927 (isolated from apple cider in Massachusetts) were obtained from the Centers for Disease Control and Prevention (CDC, Atlanta, GA).

All five strains were maintained individually in tryptic soy broth (TSB, Difco Laboratories, Detroit, MI) containing 10\% glycerol (Difco) and stored at $-80 \mathrm{C}$. These strains were partially thawed at room temperature (22-23C) for $5 \mathrm{~min}$, aseptically transferred by single loopful $\left(\sim 6.5 \log _{10} \mathrm{cfu}\right)$ to tubes containing $10 \mathrm{~mL}$ of TSB, and incubated at $37 \mathrm{C}$ for $24 \mathrm{~h}$. Each individual strain of E. coli $\mathrm{O} 157: \mathrm{H} 7$ in TSB was enumerated by serially diluting the cultures in sterile $0.1 \%$ peptone water (PW, Difco) and spiral plating (100 $\mu \mathrm{L}$, WASP, Microbiology International, Frederick, MD) onto duplicate MacConkey Sorbitol agar (SMAC, Difco) plates. Plates were incubated at 37C for $48 \mathrm{~h}$. After at least two consecutive transfers of these individual strains, equal proportions of each strain $(1 \mathrm{~mL})$ were mixed to prepare the five-strain cocktail just prior to inoculation.

\section{Meat Source}

Four boneless, USDA Select grade strip loins (longissimus muscle) were purchased within $48 \mathrm{~h}$ post slaughter from a local commercial processor (J.W. 
Treuth and Sons, Inc., Catonsville, MD). After removing the fat from the surface, the strip loins were placed in bags (Cryovac BH620T bags; Sealed Air Corp., Duncan, SC) and vacuum packaged (550A MC-40; Sipromac, Inc., St. Germain, Canada). Strip loins were stored at $-30 \mathrm{C}$ until ready for use. Prior to the experiment, strip loins were thawed at $3 \mathrm{C}$ for $48 \mathrm{~h}$.

\section{Meat Sample Preparation and Inoculation}

Strip loins were cut on clean sheets of butcher paper, with the surface fat removed. Using a sterile knife, the ends of the strip loin were removed to ensure a uniform strip loin edge (41-cm length), Then a $1.27-\mathrm{cm}$ thick steak was removed with a sterile knife for analysis of initial E. coli O157:H7 populations in meat. The remaining strip loin ( $40-\mathrm{cm}$ length) was sliced in half to yield 28 steaks for control and treatments. A brief sampling pattern is given in Fig. 1. Next, using a different sterile knife for each section, four steaks $7.5 \mathrm{~cm}$ thick were cut for use as uninoculated, raw controls. These four steaks were randomly assigned to the following treatments: Untreated cooked control (C), BT, HDP and combination of BT followed by HDP (BTH). For the untreated cooked control, the $7.5-\mathrm{cm}$ thick steak was divided into three $2.5-\mathrm{cm}$ thick steaks to be cooked to final internal temperatures of 54.4, 62.8 and 71.1C. The remaining three $7.5-\mathrm{cm}$ thick steaks were subjected to one of the following treatments: BT, HDP or BTH, then sliced into $2.5-\mathrm{cm}$ thick steaks for subsequent cooking to three final internal temperatures $(54.4,62.8$ or $71.1 \mathrm{C})$. All uninoculated control steaks were maintained at $4 \mathrm{C}$ (up to $2 \mathrm{~h}$ ) until cooked.

The remaining portion of the strip loin (25-cm length) was inoculated with the E. coli $\mathrm{O} 157: \mathrm{H} 7$ cocktail. The length and width of the strip loin was measured, and the cocktail $\left(\sim 8 \log _{10} \mathrm{cfu} / \mathrm{mL}\right)$ was applied to the entire top surface $\left(10 \mu \mathrm{L} / \mathrm{cm}^{2}\right)$ at a theoretical inoculation level of $\sim 6 \log _{10} \mathrm{cfu} / \mathrm{cm}^{2}$. The inoculum was applied using a pipette onto the meat surface and spread evenly using a bent sterile glass rod. The inoculated strip loin was placed onto a sterile tray, covered with aluminum foil, and then stored at $4 \mathrm{C}$ for $30 \mathrm{~min}$ to permit bacterial attachment to the meat surface.

After $30 \mathrm{~min}$, the inoculated strip loin was removed and placed onto clean butcher paper, inoculated side down. Using sterile knives, the $25-\mathrm{cm}$ long strip loin was cut lengthwise to produce two sections of $25-\mathrm{cm}$ length. Each section was cut in half to produce four steaks $12.5 \mathrm{~cm}$ long. These steaks were randomly assigned to the following treatments: (1) inoculated cooked control; (2) BT; (3) HDP; and (4) BTH. From the inoculated cooked control, a $2.5-\mathrm{cm}$ thick steak was cut and analyzed to determine the level of bacterial attachment. Three additional 2.5 -cm thick steaks were cut with different sterile knives from the inoculated control and were cooked to $54.4,62.8$ or 71.1C. BT-, HDP- or BTH-treated steaks were sliced into four $2.5-\mathrm{cm}$ thick steaks using sterile 


\begin{tabular}{|c|c|c|}
\hline $12.5 \mathrm{~cm}^{*}$ & $\begin{aligned} & \text { BTH } \\
\text { - } & \text { FA - 54.4C } \\
\text { - } & \text { FA - 62.8C } \\
\text { - } & \text { FA - 71.1C } \\
\text { - } & \text { BTH control }\end{aligned}$ & $\begin{array}{c}\text { HDP } \\
\text { - FA - 54.4C } \\
\text { - FA - 62.8C } \\
\text { - FA - 71.1C } \\
\text { - HDP control }\end{array}$ \\
\hline $10 \mathrm{~cm}^{*}$ & $\begin{array}{c}\text { Control } \\
\text { - } \mathrm{FA}-54.4 \mathrm{C} \\
\text { - } \mathrm{FA}-62.8 \mathrm{C} \\
\text { - } \mathrm{FA}-71.1 \mathrm{C} \\
\end{array}$ & \multirow[t]{2}{*}{$\begin{array}{c}\text { BT } \\
\text { - } \mathrm{FA}-54.4 \mathrm{C} \\
\text { - } \mathrm{FA}-62.8 \mathrm{C} \\
\text { - } \mathrm{FA}-71.1 \mathrm{C} \\
\text { - BT control }\end{array}$} \\
\hline $2.5 \mathrm{~cm}^{*}$ & Attachment & \\
\hline $7.5 \mathrm{~cm}^{*}$ & $\begin{aligned} & \text { BTH } \\
& \text { - } F A-54.4 C \\
& \text { - } F A-62.8 C \\
& \text { - } F A-71.1 C\end{aligned}$ & $\begin{array}{c}\text { HDP } \\
\text { - FA - 54.4C } \\
\text { - FA - 62.8C } \\
\text { - FA - 71.1C }\end{array}$ \\
\hline $7.5 \mathrm{~cm}^{*}$ & $\begin{aligned} & \text { BT } \\
& \text { - } \mathrm{FA}-54.4 \mathrm{C} \\
& \text { - } \mathrm{FA}-62.8 \mathrm{C} \\
& \text { - } \mathrm{FA}-71.1 \mathrm{C}\end{aligned}$ & $\begin{array}{c}\text { Control } \\
\text { - FA - 54.4C } \\
\text { - } \mathrm{FA}-62.8 \mathrm{C} \\
\text { - } \mathrm{FA}-71.1 \mathrm{C}\end{array}$ \\
\hline $.25 \mathrm{~cm}^{*}$ & Initial & \\
\hline
\end{tabular}

Inoculated

Uninoculated

FIG. 1. BEEF STRIP LOIN SAMPLING SCHEMATIC (FOR ILLUSTRATION PURPOSE ONLY, SAMPLES WERE RANDOMIZED FOR TREATMENTS)

Asterisk denotes beef steak thickness; Dotted area indicates control samples for uninoculated strip loin; BT, blade tenderization; HDP, hydrodynamic pressure treatment; $\mathrm{BTH}$, blade tenderization followed by hydrodynamic pressure treatment; FA, cooking on Farberware electric grill.

knives. One steak from each treated sample was used as the inoculated control (BT, HDP or BTH control), and three others were cooked to 54.4, 62.8 or 71.1C. Steaks were stored at 4C until cooked.

\section{Blade Tenderization}

Samples designated for BT or BTH were subjected to BT. They were placed onto a sterile cutting board with the inoculated surface on the top. Each steak was passed through a MT-M5 Ideal blade tenderizer (Lamar Ideal, 
Quebec, Canada) which produced 13 penetrations per square inch. The unit was disassembled, cleaned, and sanitized with ethyl alcohol (90\%) between samples.

\section{Hydrodynamic Pressure Processing}

For HDP and BTH, beef samples were vacuum packaged together in a multilayer barrier bag (Cryovac BH620T bags, Sealed Air Corp.) and heat shrunk in hot water (88C) for 1-2 s. The meat sample was secured at the bottom of a stainless steel shockwave container (54 L capacity) and the container was filled with water. A 100 -g binary explosive was immersed in the water $30.5 \mathrm{~cm}$ away from the meat surface (Solomon et al. 1997). The steel lid was secured and locked onto the container before the explosive was detonated.

\section{Cooking Procedure}

All steaks were cooked on open-hearth Farberware electric grills (Farberware, Yonkers, NY) to internal temperatures of 54.4, 62.8 or $71.1 \mathrm{C}$ according to American Meat Science Association (AMSA 1995) guidelines. Prior to cooking, raw steaks were threaded, using a sealed-end 16-gauge spinal needle, with a Type $\mathrm{J}$ iron-constantan Teflon Neoflon PFA high performance thermocouple wire (Omega Engineering Inc., Stamford, CT) to measure the internal temperature of the steaks during cooking. Prior to each experiment, thermocouples were calibrated using hot water. Internal temperatures were monitored using a NIST certified digital read-out thermocouple thermometer (HH-82, Omega Engineering, Stamford, CT). Steaks were turned once, at the midpoint between initial temperature and final cook temperature, using sterile tongs.

After cooking, each steak was immediately placed into a sterile Whirlpak bag (Nasco, Fort Atkinson, WI) and cooled rapidly in an ice bath for $10 \mathrm{~min}$. Rapidly cooled steaks were stored in individual bags at $4 \mathrm{C}$ for $2 \mathrm{~h}$ prior to coring.

\section{Coring Procedure}

Steaks were removed aseptically from bags and placed onto clean sheets of butcher paper. Contact with the inoculated side of each steak was avoided to prevent core contamination. Using sterile knives, approximately $2 \mathrm{~mm}$ was trimmed from the three uninoculated sides of the steak. Sterilized stainless steel coring devices $(10.1 \mathrm{~cm} \times 1.27 \mathrm{~cm}, \mathrm{G}-\mathrm{R}$ Manufacturing Co., Manhattan, $\mathrm{KS}$ ) were used to excise three cores from each steak, using a separate device for each core. The coring device was inserted from the uninoculated side of the steak and gently twisted until it pushed through the inoculated side. Steak cores were pulled from the bottom end of the coring device using a pair of 
sterile forceps. Three representative slices (resembling steak core size) were excised from each uncooked (raw) steak due to the difficulty in excising cores from raw steak. A new sterile knife was used for each slice. Cored samples were placed into a sterile filter stomacher bag (Microbiology International, Frederick, MD) and analyzed for E. coli O157:H7 populations.

\section{Bacterial Enumeration}

To determine initial concentrations of E. coli $\mathrm{O} 157: \mathrm{H} 7$ on uninoculated and inoculated steaks, steak surfaces were swabbed using a Whirl-pak "SpeciSponge" sampling kit (Nasco, Fort Atkinson, WI). The sponge was rehydrated using $15 \mathrm{~mL}$ of PW and swabbed 10 times horizontally and vertically over the measured meat surface area. After swabbing, the sponge was placed back into the bag and $10 \mathrm{~mL}$ of PW was added. The sample bag was pummeled for $1 \mathrm{~min}$ using a BagMixer (Interscience, St. Nom La Breteche, France). Appropriately diluted swab suspensions were spiral plated $(400 \mu \mathrm{L})$ onto duplicate SMAC plates followed by incubation at 37C for $48 \mathrm{~h}$.

For cooked and uncooked steak samples, three cores from each steak $(\sim 25 \mathrm{~g})$ were placed into sterile stomacher bags with a filter (Microbiology International). Cores were diluted with $0.1 \% \mathrm{PW}$, using an automatic diluter (Dilumat 3, AES Laboratoire, France) and pummeled for 2 min with a BagMixer (Interscience). The suspensions were serially diluted with PW and spiral plated $(400 \mu \mathrm{L})$ onto duplicate SMAC plates with incubation at $37 \mathrm{C}$ for $48 \mathrm{~h}$.

After incubation, all SMAC plates were electronically counted using a ProtoCOL automated colony counter (Synbiosis, Frederick, MD) and converted to $\log _{10} \mathrm{cfu} / \mathrm{g}$. Randomly selected colonies from SMAC plates were confirmed as E. coli O157:H7 with a latex agglutination test kit (Remel, Inc., Lenexa, KS).

\section{Statistical Analysis}

The mean values of two plates from each of four replicates were converted to $\log _{10} \mathrm{cfu} / \mathrm{g}$. The data were analyzed by two-way ANOVA using a "Proc Mixed" statement (SAS 8.2, Cary, NC) for effects of treatment, temperature of cooking and interactions. Heterogeneous treatment variances were modeled using variance grouping. In all cases, a statistical significance level of $P<0.05$ was used.

\section{RESULTS AND DISCUSSION}

\section{Effect of BT, HDP and BTH on E. coli 0157:H7 Survival in Raw Steaks}

Survival of five Escherichia coli $\mathrm{O} 157: \mathrm{H} 7$ strains in raw beef steaks subjected to BT, HDP or BTH revealed that there was no reduction $(P>0.05)$ 
due to any of these treatments. E. coli $\mathrm{O} 157: \mathrm{H} 7$ populations detected on control, BT-, HDP- and BTH-treated steaks were 6.36, 6.10. 6.05 and $5.91 \log _{10} \mathrm{cfu} / \mathrm{g}$, respectively. Reductions in E. coli O157:H7 populations following BT of beef steak would not be expected, however, pressure treatment may inactivate Gram-negative bacteria (Williams-Campbell and Solomon 2002). Schilling et al. (2003) and Benito-Delgado et al. (1994) reported that BT did not affect the standard plate count of beef steaks. Davis et al. (1977) attributed lower shelf life of BT-treated meat to increased psychrotrophic counts during the storage of BT-treated meat. Increased surface area and exposure of once intact meat muscle following BT might have resulted in higher psychrotrophic counts in BT-treated meat. Johnston et al. (1978) found an increase in the level of Salmonella in mechanically tenderized beef rounds compared with those in nontenderized beef rounds.

The role of HDP as a nonthermal treatment to inactivate bacterial populations in meat remains unclear because there are conflicting reports on its bactericidal effect. Researchers have shown reduction in the total plate counts in ground beef and stew pieces (Williams-Campbell and Solomon 2000, 2002) and in intact beef muscle either alone or in combination with BT treatment (Schilling et al. 2003). Furthermore, Gamble et al. (1998) reported inactivation of Trichinella spiralis in HDP-treated pork loins; however, the effect was significant only at $46 \mathrm{MPa}$ pressure. Lorca et al. (2002) did not find significant effect of HDP treatment on the natural bacterial flora of ground beef. In the present study, HDP reduced E. coli $\mathrm{O} 157: \mathrm{H} 7$ populations by approximately 0.3 logs. The bactericidal effect of HDP treatment has mostly been studied on nonpathogenic bacteria in meat. There is no published research on the effect of HDP treatment on pathogenic E. coli O157:H7 strains. Furthermore, C9490 strain, one of the five strains of E. coli $\mathrm{O} 157: \mathrm{H} 7$ used in the cocktail, was among the most pressure resistant strains and withstood $500 \mathrm{MPa}$ pressure for 5 min in HPP treatment (Robey et al. 2001). The shock waves generated during HDP treatments are in the range of $70-100 \mathrm{MPa}$ for fractions of milliseconds (Williams-Campbell and Solomon 2002). HDP treatment could be used with other antimicrobials to increase its bactericidal effects where high pressure generated during the treatment could sensitize bacteria to antimicrobial peptides or proteins (Masschalck et al. 2003). Furthermore, pressure-resistant strains could also influence its bactericidal effect.

\section{Escherichia coli O157:H7 Survival During Cooking of BT-, HDP- or BTH-treated Steaks}

Populations of E. coli O157:H7 that survived in BT-, HDP- or BTH-treated steaks after cooking to 54.4, 62.8 and $71.1 \mathrm{C}$ are shown in Table 1 . These three temperatures were used to represent undercooked (54.4C), medium rare 
TABLE 1.

SURVIVAL OF ESCHERICHIA COLI O157:H7 IN STEAKS COOKED ON FARBERWARE GRILLS FOLLOWING BT, HDP OR BTH TREATMENT

\begin{tabular}{llll}
\hline Treatment & \multicolumn{2}{l}{ EHEC counts $\left(\log _{10} \mathrm{cfu} / \mathrm{g}\right)$} \\
\cline { 2 - 4 } & \multicolumn{2}{l}{ Cook temperature } \\
\cline { 2 - 4 } & $54.4 \mathrm{C}$ & $62.8 \mathrm{C}$ & $71.1 \mathrm{C}$ \\
\hline Control & x 3.65 & xy 2.77 & y $1.15^{\mathrm{ab}}$ \\
BT & x 3.74 & xy 3.30 & y $2.20^{\mathrm{a}}$ \\
HDP & x 3.83 & xy 2.56 & ${\text { y } 1.84^{\mathrm{ab}}}^{\mathrm{b}}$ \\
BTH & x 4.22 & y 2.24 & $\mathrm{z} \mathrm{ND}^{\mathrm{b}}$ \\
\hline
\end{tabular}

a,b Values in the same column not followed by same letter are significantly different $(P<0.05)$.

$x, y, z$ Values in the same row not preceded by same letter are significantly different $(P<0.05)$.

EHEC, cocktail of five Escherichia coli O157:H7 strains; BT, blade tenderization; HDP, hydrodynamic pressure treatment; $\mathrm{BTH}$, blade tenderization followed by hydrodynamic pressure treatment; ND, nondetectable (detection limit $1.08 \log _{10} \mathrm{cfu} / \mathrm{g}$ ).

(62.8C) and medium (71.1C) cooked steaks as commonly referred by consumer cooking. As expected, the inactivation of E. coli O157:H7 increased with an increase in cooking temperature, irrespective of treatment. The populations of E. coli $\mathrm{O} 157: \mathrm{H} 7$ detected after cooking to $71.1 \mathrm{C}$ were significantly lower $(P<0.05)$ than the E. coli $\mathrm{O} 157: \mathrm{H} 7$ populations detected after cooking to 54.4C in untreated, BT-treated, HDP-treated or BTH-treated steaks. E. coli O157:H7 populations detected after cooking BTH-treated steaks to $62.8 \mathrm{C}$ $\left(2.24 \log _{10} \mathrm{cfu} / \mathrm{g}\right)$ were lower $(P<0.05)$ than those detected in BTH-treated steaks after cooking to $54.4 \mathrm{C}\left(4.22 \log _{10} \mathrm{cfu} / \mathrm{g}\right)$. At each endpoint cooking temperature, $E$. coli O157:H7 survival was always higher in BT-treated steaks than in untreated steaks cooked to corresponding temperature. This could be attributed to the migration of surface bacteria into the interior, intact muscle due to the BT treatment. The combined effect of HDP and cooking to $71.1 \mathrm{C}$ of blade-tenderized steak was the only treatment that achieved reduction of E. coli O157:H7 populations to nondetectable levels.

It is highly unlikely for pathogens to migrate below the surface of intact, untreated meat; however, BT may allow the introduction of pathogens below the surface rendering the beef steak as nonintact cuts of beef. The Food Safety and Inspection Service (FSIS 1999) updated its policy so that all ground beef and other beef that would not be sold as an intact steak, including bladetenderized steaks, would be considered adulterated if found to contain E. coli 
O157:H7. In our study, E. coli O157:H7 survival rate in BT steaks, though not significant $(P>0.05)$, was always higher than in the untreated steaks, indicating that BT introduced bacterial contamination into the interior of the muscle. There is a potential for an infective dose of E. coli $\mathrm{O} 157: \mathrm{H} 7$ to be contained in the interior of blade-tenderized beef product (Sporing 1999). Blade-tenderized steaks do not present a greater risk to consumers if the meat is oven broiled and cooked to an internal temperature of $60 \mathrm{C}$ or above in a kitchen oven (Phebus et al. 1999). In another study, we found complete inactivation of E. coli $\mathrm{O} 157: \mathrm{H} 7$ in blade-tenderized steaks cooked to an internal temperature of $71.1 \mathrm{C}$ on a George Foreman grill (unpublished data). In the present study, E. coli $\mathrm{O} 157: \mathrm{H} 7$ survived in BT steaks cooked to an internal temperature of up to $71.1 \mathrm{C}$ on open-hearth Farberware electric grills. This could be attributed to differences in cooking equipment and/or variation in heat resistance of $E$. coli $\mathrm{O} 157: \mathrm{H} 7$ strains used in the study. When intact beef muscle is blade-tenderized, hurdle treatments like HDP could be used in conjunction with cooking to enhance the inactivation of $E$. coli $\mathrm{O} 157: \mathrm{H} 7$ in such nonintact beef.

\section{CONCLUSIONS}

HDP treatment slightly reduced E. coli $\mathrm{O} 157: \mathrm{H} 7$ populations in raw intact muscle. BT had no significant effect on E. coli $\mathrm{O} 157: \mathrm{H} 7$ populations in raw beef muscle. BT treatment introduced surface bacteria into the interior of the muscle, thereby increasing the survival of pathogenic E. coli $\mathrm{O} 157: \mathrm{H} 7$ population in cooked beef steaks. This is a serious concern as BT-treated steaks may harbor pathogenic bacteria after cooking to specific endpoint temperatures as high as $71.1 \mathrm{C}$ on Farberware electric grill. A combination of $\mathrm{HDP}$ and cooking to $71 \mathrm{C}$ was required to eliminate $E$. coli $\mathrm{O} 157: \mathrm{H} 7$ populations in blade-tenderized steaks when cooked on open-hearth Farberware electric grill.

\section{ACKNOWLEDGMENTS}

We thank Brian Vinyard for providing statistical support. We also would like to thank Gabe Sanglay and Cheryl Mudd for excellent technical assistance and help in manuscript preparation.

\section{REFERENCES}

AMSA. 1995. Research Guidelines for Cookery, Sensory Evaluation and Instrumental Tenderness Measurements of Fresh Meat. Am. Meat Sci. Assoc. Nat. Livestock Meat Board, Chicago, IL. 
ANONYMOUS. 1969. Salmonellosis due to imported beef. Morb. Mort. Rep. 18(33), 285-286.

ANONYMOUS. 2003. Recall raises new E. coli issues. Meat Process. 42(7), $10-11$.

BENITO-DELGADO, J., MARRIOTT, N.G., CLAUS, J.R., WANG, H. and GRAHAM, P.P. 1994. Chuck longissimus and infraspinatus muscle characteristics as affected by rigor state, blade tenderization and calcium chloride injection. J. Food Sci. 59, 295-299.

DAVIS, G.W., SMITH, G.C. and CARPENTER, Z.L. 1977. Effect of blade tenderization on storage life, retail case life, and palatability of beef. J. Food Sci. 42, 330-337.

FSIS. 1999. Beef products contaminated with Escherichia coli O157:H7. Federal Registrar, January 9, 1999, Docket No. 97-068N.

GAMBLE, H., SOLOMON, M.B. and LONG, J.B. 1998. Effects of hydrodynamic pressure on the viability of Trichinella sipralis in pork. J. Food Prot. 61, 637-639.

GRIFFIN, P.M. and TAUXER, R.V. 1991. The epidemiology of infections caused by Escherichia coli O157:H7, other enterohemorrhagic E. coli, and the associated hemolytic uremic syndrome. Epidemiol. Rev. 13, 13-98.

HUGAS, M., GARRIGA, M. and MONFORT, J.M. 2002. New mild technologies in meat processing: High pressure as a model technology. Meat Sci. 62, 359-371.

JOHNSTON, R.W., HARRIS, M.E. and MORAN, A.B. 1978. The effect of mechanical tenderization of beef rounds inoculated with salmonellae. J. Food Safety 1, 201-209.

KOLSKY, H. 1980. Stress Waves in Solids. Dover publishing, New York, NY. LORCA, T.A., CLAUS, J.R., EIFERT, J.D., MARCY, J.E. and SUMMER, S.S. 2002. Effects of explosively-generated hydrodynamic shock wave treatments on the microbial flora of beef steaks and ground beef, and Listeria innocua. A Thesis manuscript. http://scholar.lib.vt.edu/theses/ available / etd - 07292002 - 153950 / unrestricted / applenvironmicro.pdf (accessed July 15, 2004).

MASSCHALCK, B., DECKERS, D. and MICHIELS, C.W. 2003. Sensitization of outer-membrane mutants of Salmonella typhimurium and Pseudomonas aeruginosa to antimicrobial peptides under high pressure. J. Food Prot. 66, 1360-1367.

MENG, J. and DOYLE, M.P. 1998. Escherichia coli O157:H7 and other shiga toxin producing E. coli strains. In Microbiology of Shiga Toxin Producing Escherichia coli in foods (J.B. Kaper and A.D. O'Brien, eds.) pp. 92-108, American Society for Microbiology, Washington, DC. 
MILLER, S.G. 1975. Mechanical tenderization of meat in the HRI trade. In Pro. 28th Recip. Meats Conference, Uni. of MO., Columbia, MO, pp. 134-139, Ame. Meat Sci. Asso., Chicago, IL.

PHEBUS, R., MARSDEN, J., THIPPAREDDI, H., SPORING, S. and KASTNER, C. 1999. Blade tenderization and food safety. In Proc. 52nd Recip. Meat Conference, Univ. Conn. Storrs, CT, pp. 71-72, Am. Meat Sci. Asso., Savoy, IL.

ROBEY, M., BENITO, A., HUSTON, R.H., PASCULA, C., PARK, S. and MACKEY, B.M. 2001. Variation in resistance to high hydrostatic pressure and rpoS heterogeneity in natural isolates on Escherichia coli O157:H7. Appl. Environ. Microbiol. 67, 4901-4907.

SCHILLING, M.W., MARRIOTT, N.G., WANG, H. and SOLOMON, M.B. 2003. Characteristics of USDA utility cow beef subjected to blade tenderization and hydrodynamic shock waves. J. Muscle Foods 14, 131-142.

SOLOMON, M.B. 1998. The hydrodyne process for tenderizing meat. In Proc. 51st Recip. Meat Conf. Univ. Conn., Storrs, CT, pp. 171-176. Am. Meat Sci. Asso., Kansas City, MO.

SOLOMON, M.B., LONG, J.B. and EASTRIDGE, J.S. 1997. The hydrodyne: A new process to improve beef tenderness. J. Anim. Sci. 75, 1534-1537.

SPORING, S. 1999. Escherichia coli O157:H7 risk assessment for production and cooking of blade tenderized beef steaks. Master Thesis, submitted at Kansas State University, Manhattan, KS.

WILLIAMS-CAMPBELL, A.M. and SOLOMON, M.B. 2000. New nonthermal postharvest technology to improve food safety: Hydrodynamic pressure processing. Proc. Int. Soc. Opt. Engg. 4206, 167-173.

WILLIAMS-CAMPBELL, A.M. and SOLOMON, M.B. 2002. Reduction of spoilage microorganisms in fresh beef using hydrodynamic pressure processing. J. Food Prot. 3, 571-574.

ZUCKERMAN, H. and SOLOMON, M.B. 1998. Ultrastructural changes in bovine longissimus muscle caused by the hydrodyne process. J. Muscle Foods 9, 419-426. 